\title{
COMPUTATION OF STRESS INTENSITY FACTOR OF BRASS PLATE WITH EDGE CRACK USING J-INTEGRAL TECHNIQUE
}

\author{
A. Gopichand ${ }^{1}$, Y. Srinivas ${ }^{2}$, A. V. N. L. Sharma ${ }^{3}$ \\ ${ }^{1}$ Assoc Prof, ${ }^{2}$ P.G Student, ${ }^{3}$ Prof \& Hod, Mechanical Engineering Department, swarnandhra college of engg \& tech, \\ Andhra pradesh, India, allakagopichand@gmail.com, Srinivasyarlagadda.mtech@gmail.com,avnls277522@gmail.com

\begin{abstract}
Now a days Brass is using in many industrial components like heat exchangers, bearings, valves etc. The present paper focused the principles of fracture mechanics of brass. The stress intensity factor $(S I F)$ is an important factor in fracture mechanics. J-integral method has been adopted for SIF calculation. The values obtained by using J-Integral technique have been compared with that of displacement extrapolation technique and observed that they are in order. The residual strength of brass at various crack lengths are studied.
\end{abstract}

Index Terms: Stress Intensity Factor, Residual strength, fracture toughness etc

\section{INTRODUCTION}

Fracture mechanics is a field of solid mechanics that deals with the mechanical behavior of cracked bodies. Fracture is a problem that society has faced for as long as there have been man-made structures.

Stress intensity factor is measure of the stress-field intensity near the tip of an ideal crack in a linear-elastic solid when the crack surfaces are displaced in the opening mode. basically there are two groups of estimation methods. The first group's methods are based on point matching (or extrapolation methods) techniques with nodal displacements are widely used extrapolation techniques due to its simple applicability to various crack configurations. the second group's methods are based on energy-based methods like J-Integral, energy release and the stiffness derivative methods are also used for the determination of SIF. This group requires some special postprocessing routines. Many reference books in fracture mechanics [1,2 ] and commercial finite element codes (ABAQUS, ANSYS, and COSMOS) are recommend for the energy-based methods as the most efficient for computing $\mathrm{K}_{1}$ due to relatively coarse meshes. It can give satisfactorily results with these methods.

J-Integral calculations have been done with an ANSYS macro. For this purpose, a Fortran subroutine has been developed for ANSYS which reads the results from a stress analysis and computes the appropriate line integral along a path through the integration points.

\section{J-INTEGRAL}

To determine an energy quantity that describes the elasticplastic behavior of materials, Rice [3] introduced a contour integral or line integral that encloses the crack front shown in Figure 1 originally by Eshelby

$$
J=\int_{\tau}\left(W d y-T \frac{\partial \mu}{\partial x} d s\right) \quad \ldots
$$

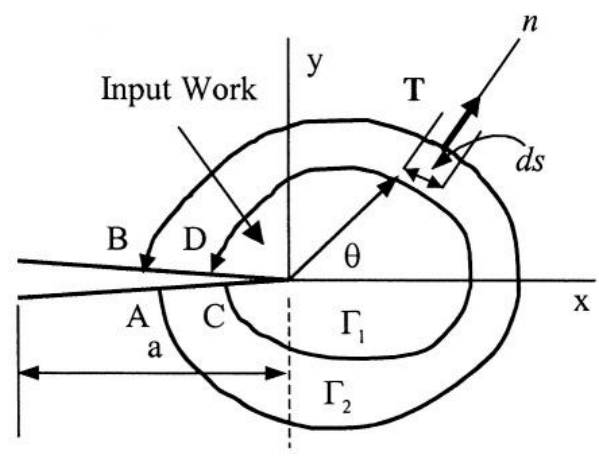

Fig1: J-integral counters around the crack surfaces

Where, $\mathrm{J}=$ Effective energy release rate (M Pa.m or M N/m)

$\mathrm{W}=$ Elastic strain energy density or plastic loading $\operatorname{work}(\mathrm{J} / \mathrm{m} 3)$

$\mu=$ Displacement vector at ds

$\mathrm{ds}=$ Differential element along the contour

$\mathrm{n}=$ Outward unit normal to $\Gamma$

$\mathrm{T}(\partial \mathrm{u} / \partial \mathrm{x}) \mathrm{ds}=$ Input work

$\mathrm{a}=$ Crack length

$\mathrm{T}=$ Tension vector on the body bounded by $\mathrm{r}$

$\Gamma=$ Arbitrary counterclockwise contour

The term $\mathrm{J}$ in eq. (1) is a line of surface integral defined around a contour $\Gamma$ It characterizes the stress-strain field around the crack front and therefore, it must be the energy release to the 
crack tip during crack growth. Due to this fact, the J-integral is used as failure criterion and it is a measure of the fracture toughness at the onset of slow crack growth for elastic and elastic-plastic metallic materials. The inherent characteristics of the J-integral exhibits a) remarkable path, contour size and shape independence, and b) an invariability in magnitude when the contour lies either inside or outside the plastic zone [4]. The former characteristic indicates that the $\mathrm{J}$-integral vanishes $(\mathrm{J}=$ 0 ) around an arbitrary closed contour as shown by Parton and Morozov [5] using Green's formula.

In this j-integral method program can be used for calculating stress intensity factor, the program will be used to define the path nodes to which is used to finding the jint value, by input read input program to the file the using the scalar parameters command we obtain the jint value, it will change by chaining the path and as well as crack length, after obtain the jint value we can calculate stress intensity factor by the give formula for plane strain condition,

Stress Intensity Factor,

$$
K_{2}=\sqrt{\frac{J_{2} E}{1-v^{2}}}
$$

Where,

$\mathrm{K},=$ Stress intensity factor

$\mathrm{J},=\mathrm{J}$-Integral value

$\mathrm{E}=$ Young's modulus

$v=$ Poisson's Ratio

\section{BRASS MATERIAL (CU70ZN30, ANNELEAD):}

Brass is usually the first-choice material for many of the components for equipment made in the general, electrical and precision engineering industries. Brass is specified because of the unique combination of properties, matched by no other material, that make it indispensable where a long, cost-effective service life is required.

The generic term 'brass' covers a wide range of copper-zinc alloys with differing combinations of properties, including:

- Strength - Machinability

- Ductility - Wear resistance

- Hardness • Colour

- Conductivity $\cdot$ Corrosion resistance

Brasses can easily be cast to shape or fabricated by extrusion , rolling, drawing, hot stamping and cold forming.

- The machinability of brass sets the standard by which other materials are judged.

- Brasses are ideal for a very wide range of applications.

- Brass is frequently the cheapest material to select.

- The correct choice of brass is important if manufacturing and operating requirements are to be met in the most cost- effective way.

Table1: Mechanical Properties

\begin{tabular}{|c|c|}
\hline \multicolumn{2}{|c|}{ BRASS $(\mathbf{7 0 C U 3 0 Z N , ~ A N N E A L E D )}$} \\
\hline Density $(r, \mathrm{Mg} / \mathrm{m} 3)$ & 8.4 \\
\hline Young's Modulus $(E, \mathrm{GPa})$ & 130 \\
\hline Shear Modulus $(G, \mathrm{GPa})$ & 39 \\
\hline Poisson's Ratio $(n)$ & 0.33 \\
\hline Yield Stress $(s Y, \mathrm{MPa})$ & 75 \\
\hline Breaking strain $(e f, \%)$ & 70 \\
\hline UTS $(s f, \mathrm{MPa})$ & 325 \\
\hline Fracture Toughness $\left(K c, \mathrm{MN} \mathrm{m}\left(^{-3 / 2}\right)\right.$ & $2400 \mathrm{Nm}^{(-3 / 2)}$ \\
\hline Thermal Expansion $\left(a, 10^{-6} / \mathrm{C}\right)$ & 20 \\
\hline
\end{tabular}

\section{Applications:}

Typical applications include: Heat Exchangers, Bearings Architecture, grillwork, appliances, drawn \& spun containers and components, radiator cores and tanks, electrical terminals, plugs and lamp fittings, locks, door handles, name plates, plumbers hardware, fasteners, cartridge cases, cylinder liners for pumps.

\section{Available forms:}

Austral Wright Metals can supply this alloy as coil, sheet, plate, rods, bars, sections.

\section{DETERMINATION OF J VALUE:}

\section{Modeling Of Brass Plate[6]:}

Creating Key points

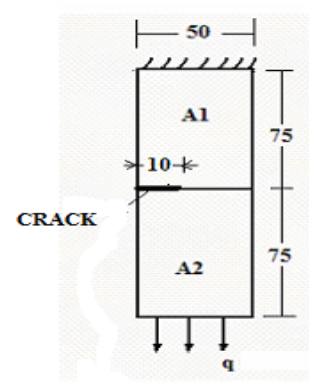

Figure 2: Plate with Edge Crack

Table 2: Keypoints Data

\begin{tabular}{|c|c|c|}
\hline Key points \# & $\mathbf{X}$ & $\mathbf{Y}$ \\
\hline 1 & 40 & 0 \\
\hline 2 & 0 & 0 \\
\hline 3 & -10 & 0 \\
\hline & -10 & 0 \\
\hline
\end{tabular}




\begin{tabular}{|c|c|c|}
\hline 5 & 40 & 75 \\
\hline 6 & -10 & 75 \\
\hline 7 & 40 & -75 \\
\hline 8 & -10 & -75 \\
\hline
\end{tabular}
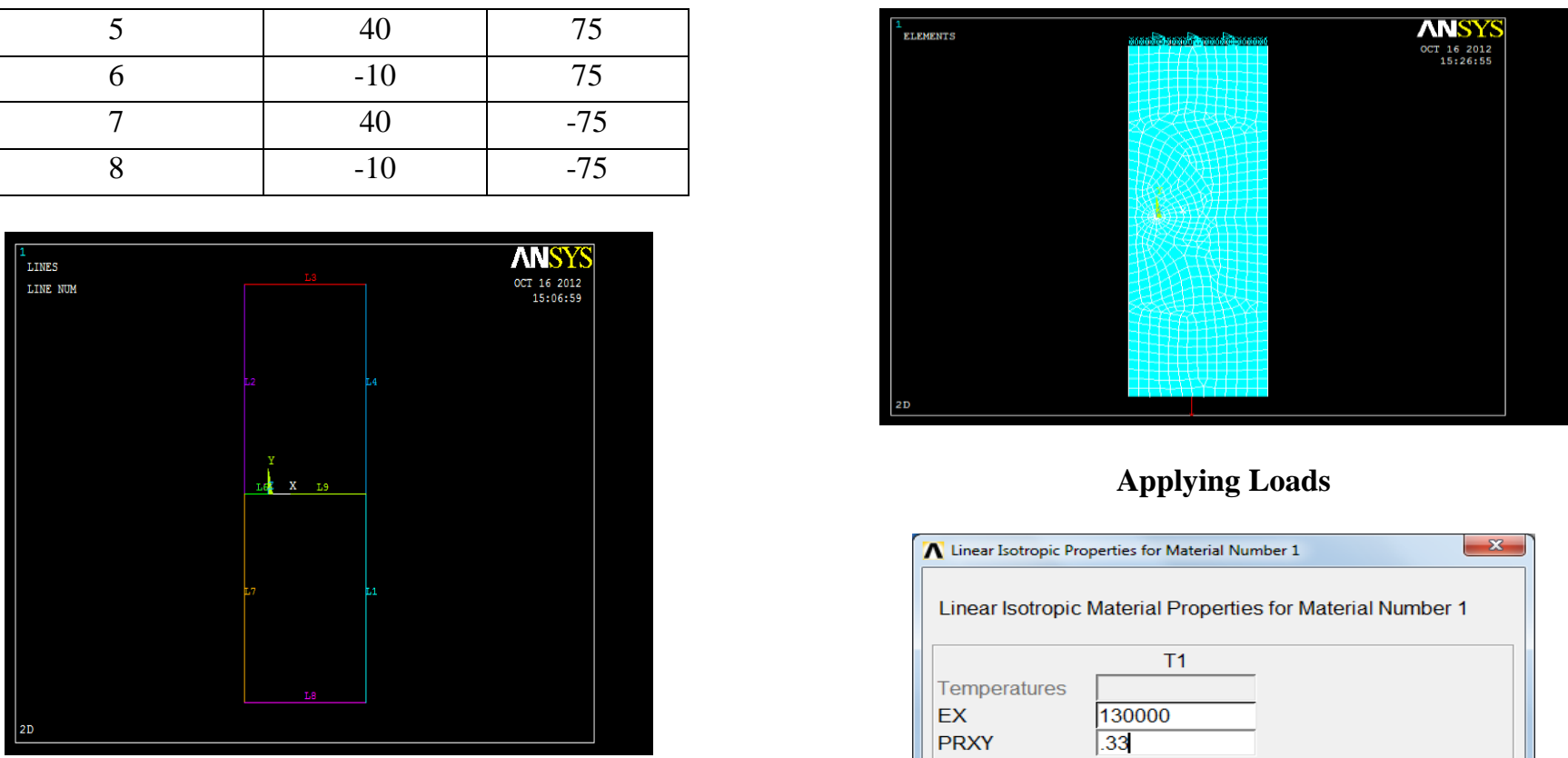

Applying Loads
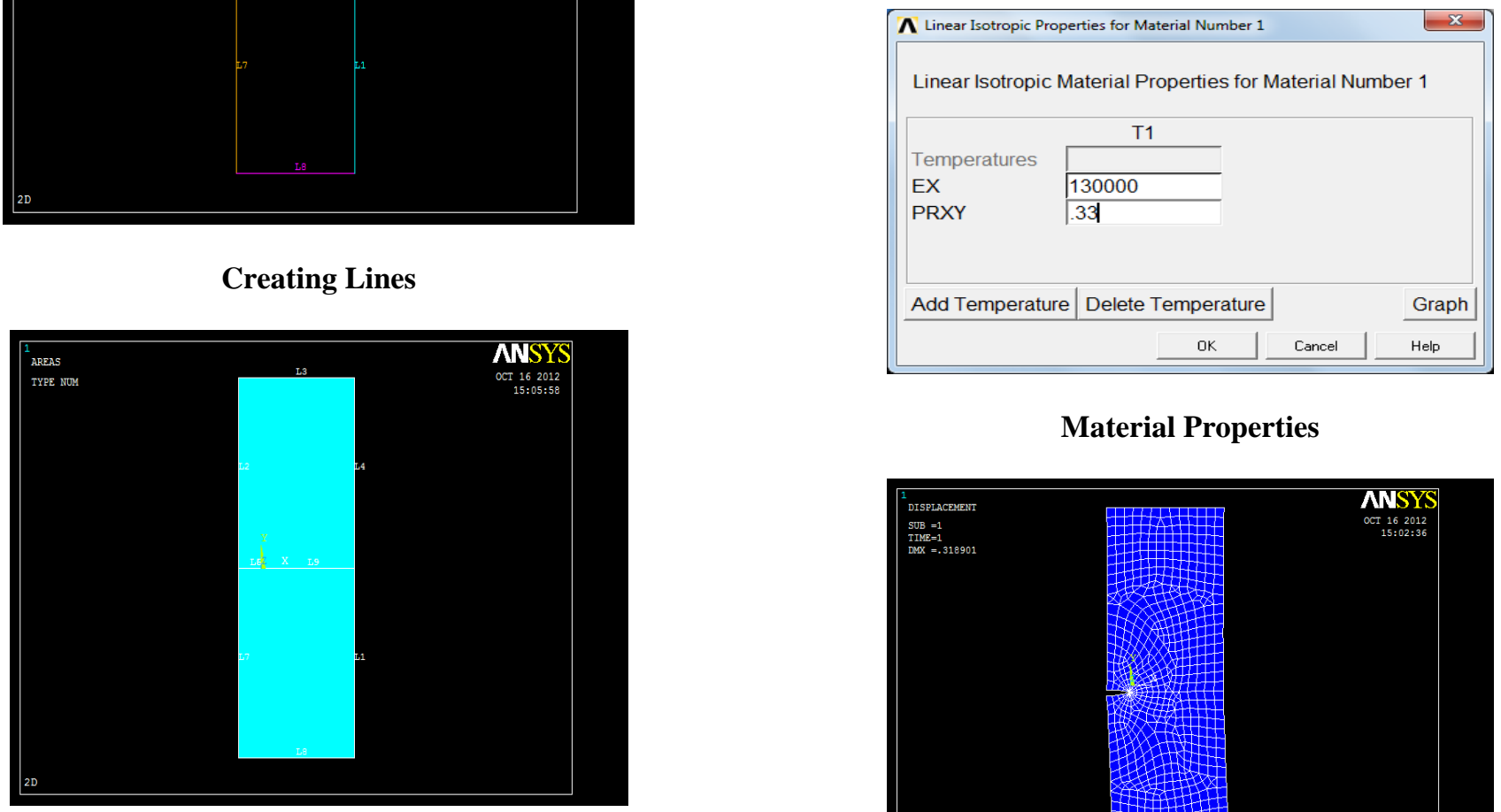

Material Properties

Creating Areas
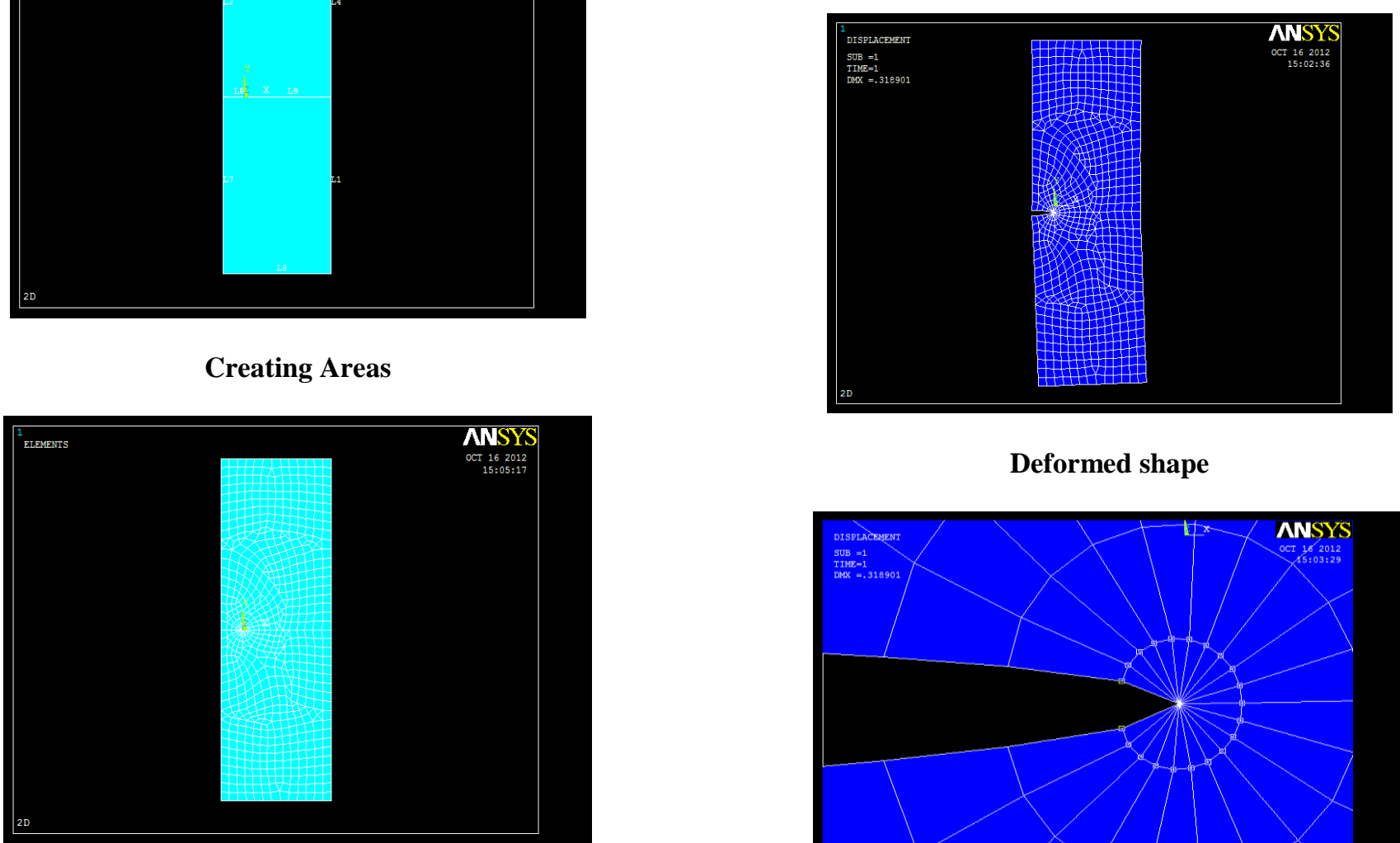

Deformed shape

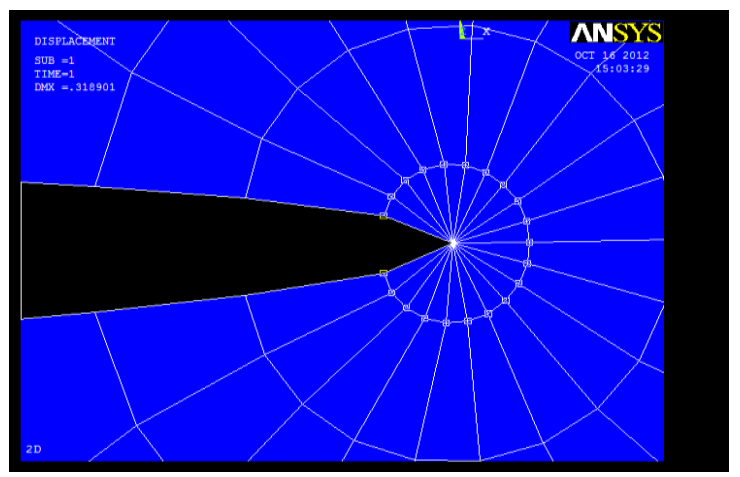

Path P1 


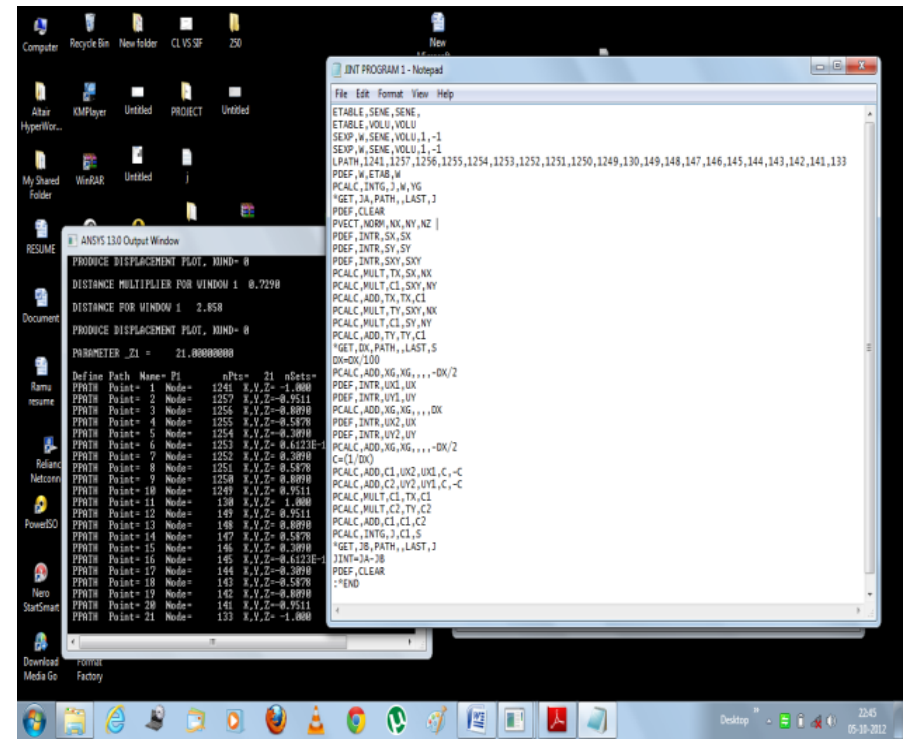

J-intergral commands

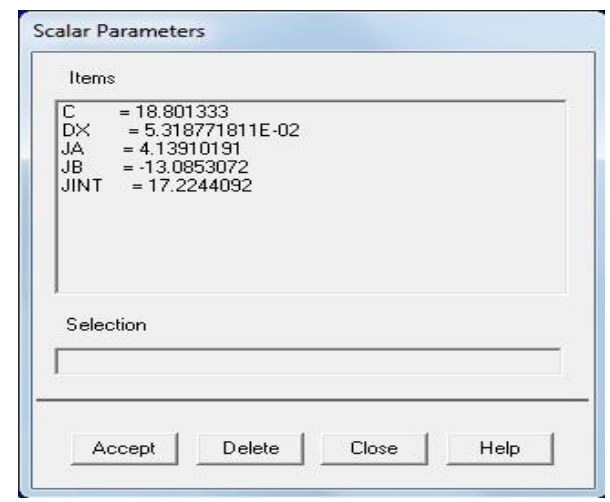

J-Integral Value for Path -1

Similarly for paths P2 ,P3, P4, P5 as shown in the figure done the same process and obtain the JINT values as 17.224, $18.548,20.087,20.362,20.436$ respectively.

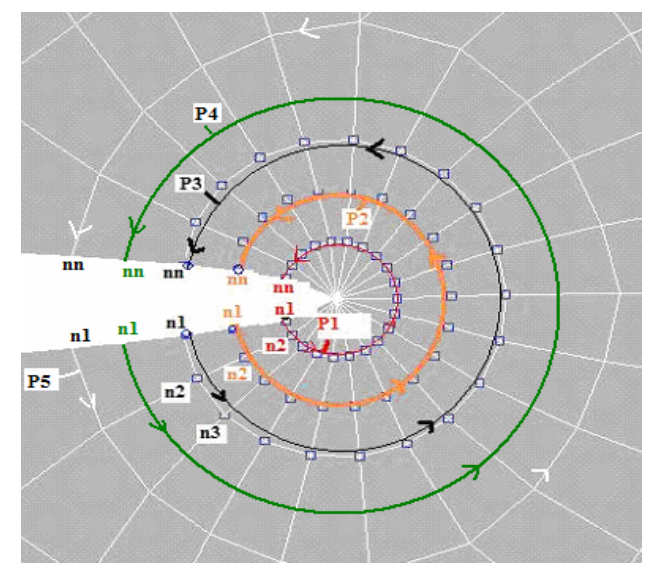

Figure 5: PATHS OF P1, P2, P3, P4, P5
J-Integral values

For 5 Paths at load 230N/mm and $10 \mathrm{~mm}$ crack length

Table 3: Jint Values For 5 Paths

\begin{tabular}{|l|l|}
\hline PATHS & JINT VALUE \\
\hline P1 & 17.224 \\
\hline P2 & 18.548 \\
\hline P3 & 20.087 \\
\hline P4 & 20.367 \\
\hline P5 & 20.436 \\
\hline
\end{tabular}

J-int avg value $=(17.224+18.548+20.087+20.362+20.436) / 5$

$96.657 / 5$

$\mathrm{J},=19.3314$

\section{Calculation of K Value:}

\subsection{BY J-INTEGRAL METHOD:}

Stress Intensity Factor,

$$
K_{2}=\sqrt{\frac{J_{2} E}{1-v^{2}}}
$$

Where,

$$
\begin{gathered}
\mathrm{K},=\text { Stress intensity factor } \\
\mathrm{J},=\mathrm{J} \text {-Integral value } \\
\mathrm{E}=\text { Young's modulus } \\
\vartheta=\text { Poisson's Ratio } \\
\text { i.e } \mathrm{J},=19.3314 \\
\mathrm{E}=130000 \mathrm{Mpa} \\
\vartheta=0.33 \\
\mathrm{~K}=\sqrt{ } 19.3314 * 130000 / 1-(0.33) 2 \\
=\sqrt{ } 2513082 / 0.8911 \\
=\sqrt{ } 2820202 \\
\mathrm{~K},=1679.34 \mathrm{~N} \backslash \mathrm{mm}(-3 / 2)
\end{gathered}
$$

where K J-INT = Stress Intensity factor by j-integral method,

$\mathrm{K} T \mathrm{Th}=$ 'Stress Intensity factor by theoretical method

$\%$ Error $=\mathrm{K} \mathrm{J}$-INT $/ \mathrm{K} \mathrm{T} \mathrm{h}$

$$
\begin{aligned}
& =1679.34 / 1744.4 \\
& =0.9627
\end{aligned}
$$

$1-0.9627=0.03729$

Error $=3.7 \%$

\subsection{BY THEORETICAL METHOD :}

$\mathrm{K},=\alpha \sigma \sqrt{\pi \mathrm{a}}$

$\alpha=1.12-0.23(\mathrm{a} / \mathrm{w})+10.55(\mathrm{a} / \mathrm{w}) 2-21.71(\mathrm{a} / \mathrm{w}) 3+30.38$

(a / w) 4

where $\alpha=$ crack geometric correlation factor

$\sigma=$ load

$\mathrm{a}=$ crack length

$\mathrm{w}=$ specimen width 


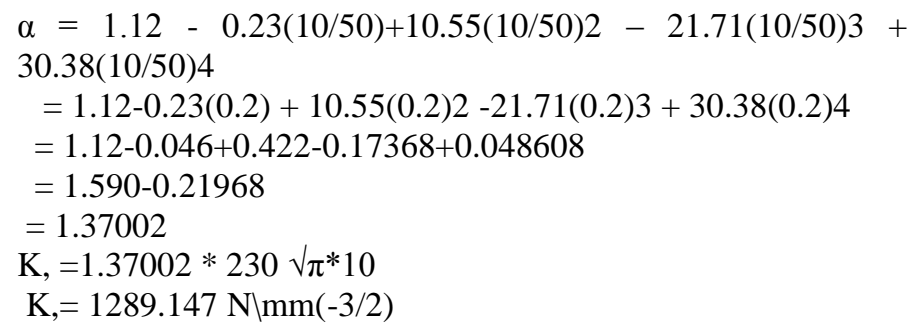

\subsection{BY DISPLACEMENT EXTRAPOLATION METHOD:}

In this method we select the nodes at the front of the crack

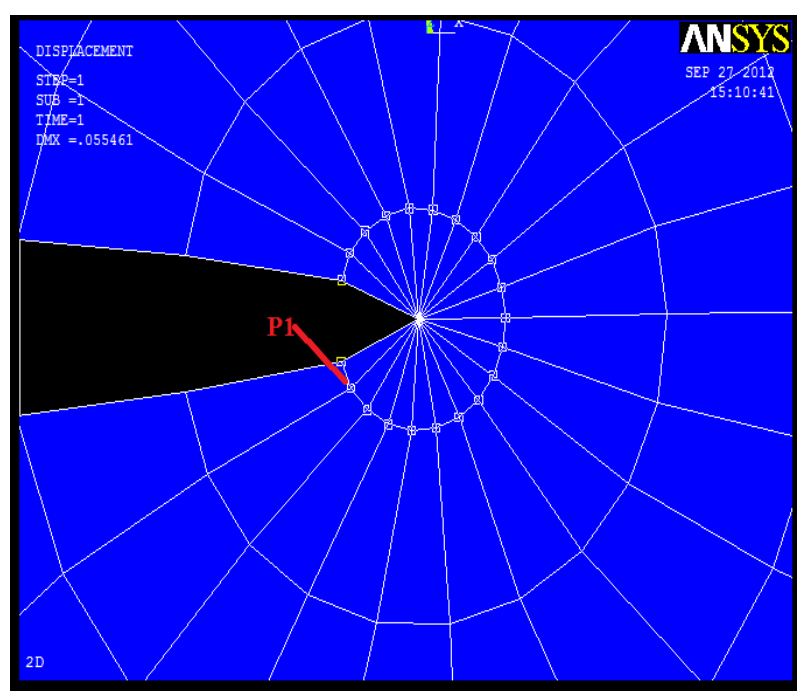

Figure 6: Selecting 5 Nodes

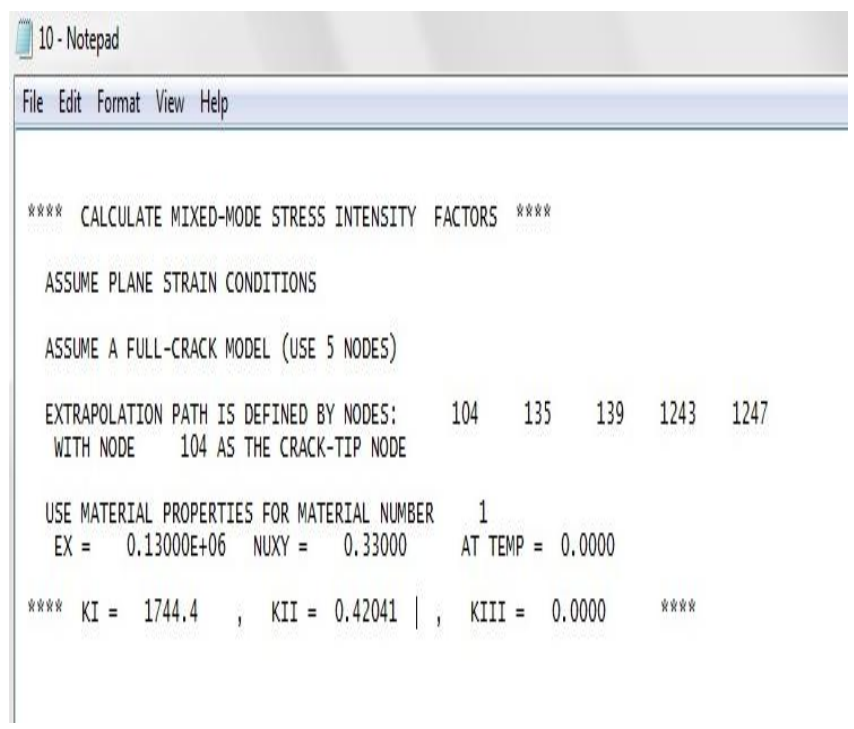

\section{$K$ value using Displacement extrapolation}

Similarly for different crack lengths $10,11,12,13,14$ at load 230, 250 and $270 \mathrm{~N} / \mathrm{mm}$ as tabulated below
Table 4: Comparison of Stress Intensity Factor by J-Integral and Displacement Extrapolation methods

\begin{tabular}{|c|c|c|c|c|}
\hline S.NO & $\begin{array}{l}\text { CRACK } \\
\text { LENGTH }\end{array}$ & $\begin{array}{c}\text { DISP } \\
\text { EXTRAPOLATION }\end{array}$ & $\begin{array}{c}\mathrm{J}- \\
\text { INTEGRAL }\end{array}$ & $\begin{array}{r}\% \\
\text { error }\end{array}$ \\
\hline \multicolumn{5}{|c|}{ ATLOAD $230 \mathrm{Nmm}$} \\
\hline 1 & 10 & 1744.40 & 1679.34 & 3.7 \\
\hline 2 & 11 & 1899.20 & 1829.00 & 3.6 \\
\hline 3 & 12 & 2022.01 & 1962.60 & 2.9 \\
\hline 4 & 13 & 2235.00 & 2134.52 & 4.4 \\
\hline 5 & 14 & 2419.10 & 2320.10 & 4.0 \\
\hline 6 & 15 & 256531 & 2479.04 & 3.3 \\
\hline \multicolumn{5}{|c|}{ ATLOAD $250 \mathrm{Nmm}$} \\
\hline 1 & 10 & 1896.10 & 1825.39 & 3.7 \\
\hline 2 & 11 & 2064.30 & 1988.75 & 3.6 \\
\hline 3 & 12 & 2197.85 & 2119.45 & 3.5 \\
\hline 4 & 13 & 2429.60 & 2320.13 & 4.5 \\
\hline 5 & 14 & 2629.5 & 2521.85 & 4.0 \\
\hline \multicolumn{5}{|c|}{$\frac{1}{\text { ATLOAD } 270 \mathrm{Nmm}}$} \\
\hline 1 & 10 & 2047.70 & 1971.41 & 3.7 \\
\hline 2 & 11 & 2229.50 & 2147.85 & 3.6 \\
\hline 3 & 12 & 2373.70 & 2303.94 & 2.9 \\
\hline 4 & 13 & 2624.00 & 2505.75 & 4.5 \\
\hline
\end{tabular}

\section{RESIDUAL STRENGTH CURVE:}

In general, the construction of a residual strength diagram involves three steps:

(a) The development of the relationship between the applied stress $\sigma$, the crack length parameter $a$, and the applied stress-intensity factor $K$ for the given structural configuration.

(b) The selection of an appropriate failure criterion based for the expected material behavior at the crack tip.

(c) The fracture strength $(\sigma f)$ values for critical crack sizes $\left(a_{C}\right)$ are obtained utilizing the results of the first two steps and residual strength diagram ( $\left.\sigma f v_{s} a_{C}\right)$ for the given structural configuration is plotted.

The above steps are explained clearly in graphical method using the following steps.

Step 1: Construct a plot of $\mathrm{K}_{\mathrm{s}}$ a by using the equation in step 1 for various values of stress and crack lengths.

Step 2: Superimpose the horizontal line $K=K_{\mathrm{cr}}=2400 \mathrm{~N} / \mathrm{mm}^{(-}$ ${ }^{3 / 2)}$ on the diagram. This line represents the critical stress intensity, i.e., fracture toughness, for this material and is independent of crack length.

Step 3: Complete the residual strength diagram, utilize the intersection line with curves where the failure criterion is satisfied, i.e., where $\mathrm{K}_{\mathrm{cr}}=\mathrm{K}=\alpha \sigma \sqrt{\pi \mathrm{a}}$ The values of the respective stresses and the crack sizes these points are termed to be the failure stresses and the critical crack sizes for the 
given structures, i.e., model. The residual strength diagram is finally constructed by plotting the $\sigma_{f} \mathrm{v}_{\mathrm{s} .} a_{c}$ curve.

Based on the following steps critical crack length has been calculated for the following loads $230 \mathrm{~N} / \mathrm{mm}, 250 \mathrm{~N} / \mathrm{mm}, 270$ $\mathrm{N} / \mathrm{mm}$ by the reference of residual strength diagram, the following diagram shows the residual strength.

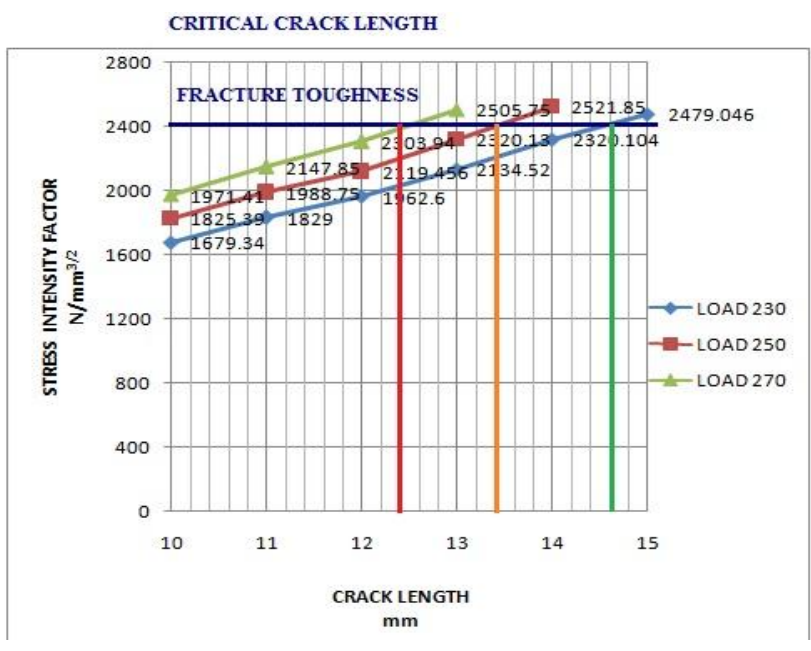

Determination of Critical Crack Length

Table 5: Critical Crack Lengths

\begin{tabular}{|c|c|c|}
\hline S.NO & $\begin{array}{l}\text { Load } \\
\text { N/mm }\end{array}$ & $\begin{array}{l}\text { Critical Crack } \\
\text { Length } \mathbf{~ m m}\end{array}$ \\
\hline 1 & 230 & 14.6 \\
\hline 2 & 250 & 13.4 \\
\hline 3 & 270 & 12.4 \\
\hline
\end{tabular}

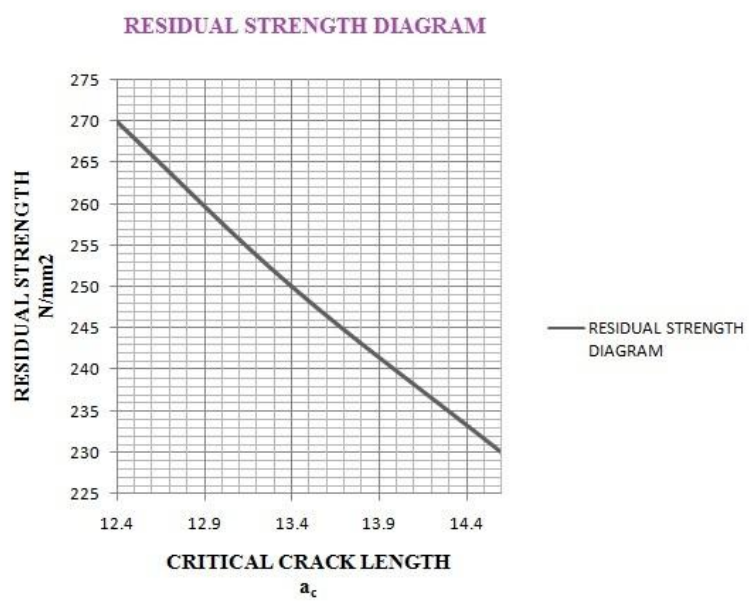

\section{CONCLUSIONS}

In this paper we used two different techniques for the calculation of SIF $\mathrm{K}_{\mathrm{I}}$ of brass plate with edge crack, the two techniques carried out were the Displacement Extrapolation Technique, J- Integral technique, The critical crack length is calculated for loads $230 \mathrm{~N} / \mathrm{mm}, 250 \mathrm{~N} / \mathrm{mm}, 270 \mathrm{~N} / \mathrm{mm}$ are $14.6 \mathrm{~mm}, 13.4 \mathrm{~mm}, 12.4 \mathrm{~mm}$. From this study, it has been observed that SIF value increases with increase in crack length and the component failed when the SIF reaches its critical value i.e. fracture toughness Using the residual strength diagram the propagation of the crack for different loads are studied.

\section{REFERENCES}

[1]. .Tada H, PC Paris, GR Irwin, The stress analysis of cracks handbook. ASME Press, 2000.

[2]. Kanninen MF, Popelar CH, Advanced fracture mechanics. Newyork, Oxford University Press, 1985.

[3]. .J.R. Rice, J. Appl. Mech. 35 (1968) 379-386.

[4]. E.M. Morozov and G.P. Nikishkov, "Finite Element Method in Fracture Mechanics," Nauka, Moscow, (1980), referencecitedin].

[5].V.Z. Parton and E.M. Morozov, "Mechanics of ElasticPlastic Fracture," second edition, Hemisphere publishing corporation, New York, (1989).

[6]. Ansys 13.0 Theory and Reference Manual, 2010.

\section{BIOGRAPHIES:}

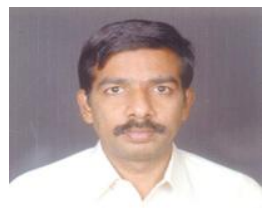

A. Gopichand M.Tech(Ph.D) Associate Professor, Mechanical Engineering Department, Swarnandhra College of Engg \& tech, Andhra Pradesh, India Having 16 years experience, Published three international journals, three international conference publications.

Y. Srinivas (M.Tech), Mechanical Department, Swarnandhra College of Engg $\&$ tech, Andhra Pradesh, India.

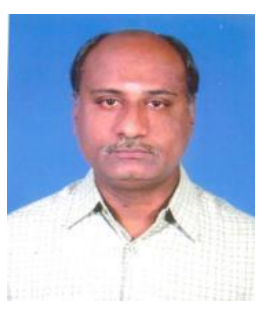

A. V. N. L. Sharma, Professor \&Hod, Mechanical Engineering Department, swarnandhra college of engg \& tech, Andhra pradesh, India, 23 Years teaching experience, Having 6 international journal publications .and 4 international conference publications

Figure 8: Residual Strength Diagram 